\title{
Behavioral Intention towards the Use of 3G Technology
}

\author{
Sona Mardikyan, Betül Beşiroğlu and Gözde Uzmaya \\ Department of Management Information Systems, Bogazici University, Istanbul, Turkey
}

\begin{abstract}
Nowadays, 3G technologies provide people with higher wireless bandwidth, audio and video services, as well as mobile internet access all in one mobile environment. The information technology industry needs to understand why people prefer this technology, which variables and opportunities convinced them to use it. The focus of this study is to examine the factors affecting 3G technology perception and adoption. In the theoretical framework of the study, Technology Acceptance Model (TAM) and Unified Theory of Acceptance and Use of Technology (UTAUT) are used as guidelines. In order to analyze 3G users' perception and behavioral intention, external variables (perceived usefulness, perceived ease of use, price, variety of 3G services, service quality and social influence) and control variables (gender, age, education level, experience, occupation, payment type) are analyzed through a survey study. The results show that perceived usefulness, variety of $3 \mathrm{G}$ services, service quality and social influence are influencing factors towards the behavioral intention of $3 \mathrm{G}$ usage.
\end{abstract}

Keywords: 3G Technology, Usage, Behavioral Intention, Adoption.

\section{Introduction}

Mobile telecommunication system continuously progresses with the advancement of technology and the users' demands towards transmission speed and application services. The acceleration of the demand for high speed data services and the spreading of mobile communication have also increased the demand for high speed mobile services. Parallel to these tendencies, studies for investing and developing new technologies in communication have been initiated. Mobile services and $3 \mathrm{G}$ technologies have become a fundamental part of people's lives throughout the world. There has been a steady growth in worldwide 3G mobile adoption. Mobile internet adoption is expected to exhibit a fast growth in the following years, achieving up to $40 \%$ of total subscribers in 2013. However, there also exists a wide range of $3 \mathrm{G}$ diffusion levels in countries. In Turkey, with the start of 3G service delivery in July 2009, the number of 3G subscribers reached 19.4 million at the end of December, 2010.

Understanding the behavioral adoption requirements is important to both researchers and industry players. Researches on 3G technology acceptance and adoption provide worthy information on 3G mobile Internet development and implementation. It is thus imperative to understand the interplay of factors involved in the adoption of this technology. The purpose of this study is to analyze the important factors of $3 \mathrm{G}$ perception and adoption using the Technology Acceptance Model (TAM) and Unified Theory of acceptance and Use of Technology (UTAUT) as the guiding principles.

\section{Literature Review}

The Technology Acceptance Model (TAM) (Davis et al., 1989) has been considered the most useful for predicting the acceptance of information technology in consumer

Copyright (C) 2012 Sona Mardikyan, Betül Beșiroğlu and Gözde Uzmaya. This is an open access article distributed under the Creative Commons Attribution License unported 3.0, which permits unrestricted use, distribution, and reproduction in any medium, provided that original work is properly cited. Contact author: Sona Mardikyan E-mail: mardikya@boun.edu.tr 
context. The theoretical constructs of TAM consist of two basic determinants for attitudes to use a specific system: perceived usefulness and perceived ease of use.

Some researchers found several additional components for TAM that are very important in users' behaviors, such as human and social change processes (Legris et al., 2003), social influence processes (subjective norm, voluntariness and image) and cognitive instrumental processes (job relevance, output quality, result demonstrability and perceived ease of use) (Venkatesh and Davis, 2000).

Susan et al. (2006) examined students' perceptions and their acceptance of implementing a laptop program by adopting TAM as the theoretical framework. Cheong and Park (2005) adopted an extend TAM model to explore consumer's determinant of acceptance behaviors in using the mobile internet. They added several additional value components in extension of the original TAM model, such as perceived system quality, perceived content quality, perceived playfulness, perceived price level and internet experience. Park et al. (2011) and Fadare et al. (2011) investigated the factors affecting students' behavioral intention to use mobile learning based mainly on the TAM. In another study, the TAM is used to analyze internet adoption and use among men and women in Indonesia (Wahid, 2007).

The Unified Theory of Acceptance and Use of Technology (UTAUT) (Venkatesh et al., 2003 ) is an integration of eight previous IT acceptance models that includes: Theory of Reasoned Action (TRA); Technology Acceptance Model (TAM); Motivational model; Theory of Planned Behavior (TPB); Combined TAM-TPB; Model of PC Utilization; Innovation Diffusion Theory; and Social Cognitive Theory. The model theorized that four constructs will play a significant role as direct determinants of user acceptance and usage behavior: performance expectancy, effort expectancy, social influence and facilitating conditions. Four additional criteria including gender, age, education and voluntariness of use are labeled as key moderators or significant moderating influences on behavioral intention.

Several studies were conducted to understand the factors affecting 3G adoption so far. In the study of Agarwal et al. (2007), the researchers have examined the interplay of actors in the adoption process of $3 \mathrm{G}$ and the impact of external variables like convenience, self efficacy, service quality, price and variety of service on user adoption of this technology. As a result of the study, price, convenience and service quality are all essential to perceived value. The relationship between variety of service and perceived value is mediated by convenience. The study also concluded that perceived value has a strong relationship with purchase intention. A different study to understand factors which influence the users' intention to 3G adoption was conducted by Phuangthong and Malisawan (2005). This research primarily aims to examine the factors affecting the user adoption in mobile learning of $3 \mathrm{G}$ mobile Internet technology in Thailand by using TAM. In their model, user acceptance is examined by attitude towards use and intention to use, rather than actual use due to the fact that $3 \mathrm{G}$ technology is still at an early stage. As a result, TAM for $3 \mathrm{G}$ mobile internet proposes a framework for understanding, explaining and predicting factors that influence individual acceptance of 3G mobile internet. The purpose of the study by $\mathrm{Wu}$ et al. (2008) is mainly to verify the suitability of UTAUT model for $3 \mathrm{G}$ telecommunication services. The study dimensions are performance expectancy, effort expectancy, social influence and facilitating conditions as external variables; gender, age, experience, voluntariness of use and education as control variables. According to this study, the significant factors affecting the behavioral intention of 3G telecommunication services are performance expectancy, social influence, and facilitating conditions, whereas the effort expectancy is not.

Karjaluoto (2006) discusses 3G networks and services from a marketing perspective. This study investigates the success factors 
and user acceptance of the 3G mobile network and its services. The importance of the antecedents of 3G's success by outlining the underlying factors: namely standardization, user acceptance, and pricing, which are among the influential factors affecting the development and marketing of successful 3G services. The aim of the study by Singh et al. (2010) is to examine the factors affecting the adoption of 3G services among Indian people. It adopts the revised Technology Acceptance Model by adding five antecedentsperceived risks, cost of adoption, perceived service quality, subjective norms, and perceived lack of knowledge. Kuo and Yen (2009) investigate the behavioral intention to use $3 \mathrm{G}$ mobile value-added services by adopting the TAM. In the proposed model, two additional factors, incorporate personal innovativeness and perceived cost are taken into consideration. Another research by Suki (2011) examines the relationship between perceived usefulness, perceived ease of use, perceived enjoyment, attitude and subscribers' intention towards using 3G mobile services with the Technology Acceptance Model (TAM) as the guiding principle. The consequences of this study show that subscribers' intention to use $3 \mathrm{G}$ mobile services is determined by their perception of its usefulness and how convenient it is to use and access 3G mobile services' functions.

\section{Research Model}

After an elaborated investigation on mobile communication and 3G technology together with user attitudes, the researchers developed a final model in which most of the external and control variables are derived from our extensive literature review. On the basis of identified variables, the researches aim to understand the intention for the usage of $3 \mathrm{G}$ technology. Figure 1 represents the model of our framework, showing the external and the control variables together with their relationship.

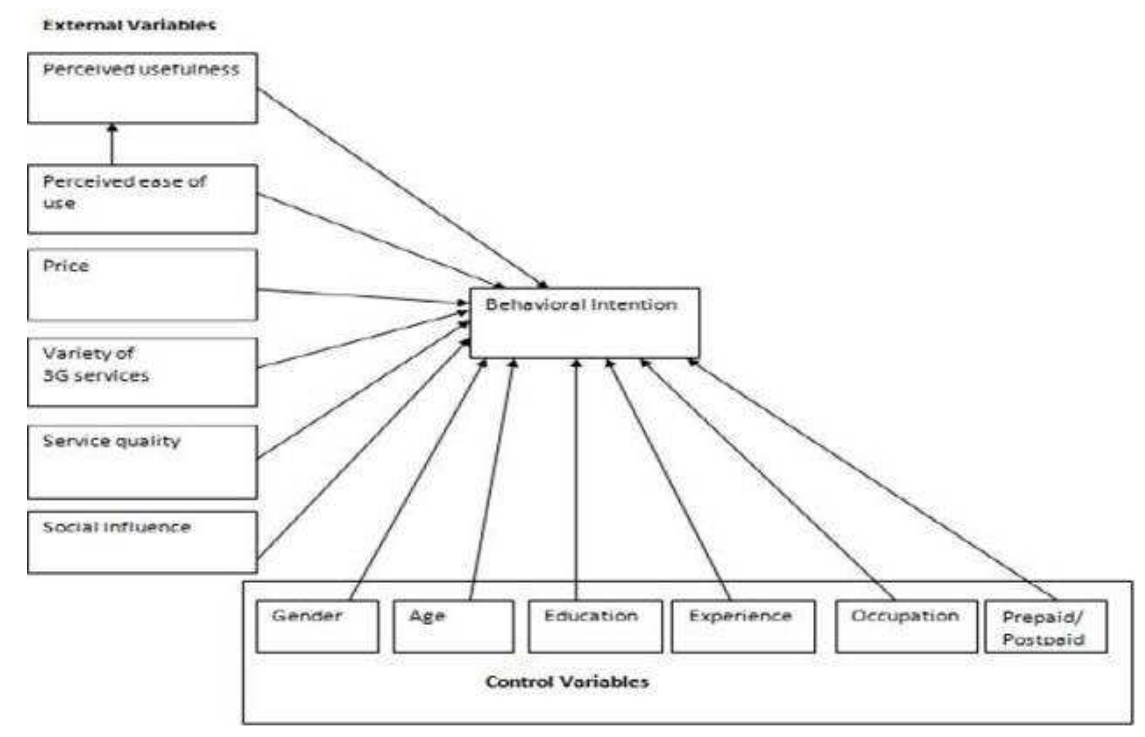

Fig 1. The Research Model

The following paragraphs include brief explanations of our external and control variables.

\section{External Variables of the Study}

Perceived Usefulness: Several studies (Davis, 1989; Davis et al., 1989; Pagani,
2004; Park et al., 2011; Fadare et al., 2011) have shown that perceived usefulness is a strong determinant of user acceptance, adoption and usage behavior.

Perceived Ease of Use: In TAM, perceived ease of use is defined as the extent to which a person believes that using a technology 
will be simple. Many studies (Davis, 1989; Vankatesh, 2000; Pagani, 2004; Kuo and Yen, 2009; Suki, 2011; Park et al., 2011; Fadare et al., 2011; Suki and Suki, 2011) show that perceived ease of use is beneficial for initial acceptance of an innovation and is essential for adoption and continued use.

Price: Pricing of the $3 G$ services is definitely one of the factors that contribute to the success of 3G (Pagani, 2004; Karjaluoto, 2006; Agarwal et al., 2007; Kuo and Yen, 2009; Indrawati et al., 2010; Park et al., 2011; Suki and Suki, 2011).

Variety of Services: 3G provides a wide variety of audio, video and data services. The larger a range of services is, the more powerful the technology. Therefore, greater variety of service can add more value to its consumers (Agarwal et al., 2007).

Service Quality: Service quality is defined as the perceived quality of service from a customer's point of view rather than real system quality (Bienstock et al., 2008). In many service industries, companies have created programs which incorporate a survey that elicits customers' assessments of service quality. Perceived service quality may influence attitudes towards using 3G services and intention to use these services (Singh et al., 2010).

Social Influence: Some researchers believe that use intention of a new technology is influenced by the social environment of people. Therefore, there may be a significant relationship between social influence and behavioral intention (Venkatesh et al., 2003; Wu et al., 2008; Indrawati et al., 2010).

In the present model, the researchers aim to investigate the impact of the following external variables: perceived usefulness, perceived ease of use, price variety of services, service quality, and social influence on users' behavioral intention to use $3 \mathrm{G}$ technologies.

\section{Control Variables}

It is believed that user intention would be influenced by the interfering factors such as gender, age, experience (Venkatesh et al., 2003). In the current study, besides these control variables, it is assumed that education level, occupation and payment type (prepaid/postpaid) may have effect on users' behavioral intention to use 3G Technology. Since they may be indicators of 3G technology user perception and adoption, the researchers added education, occupation and payment type as control variables.

\section{Data Preparation and Methodology}

Cross-sectional data were collected based on the literature review and the research model.

\section{Data Preparation}

Considering the literature review, a questionnaire including 13 questions (representing each variable of the study) was prepared and sent to 180 people. 150 valid responses returned. Respondents were located in different districts of Istanbul. The sample was selected from two types of people: users of 3G technology and potential users for 3G technology. People who use 3G technology gave information about $3 \mathrm{G}$ adoption and people who are potential users for $3 \mathrm{G}$ technology gave information about $3 \mathrm{G}$ perception.

Each question of the questionnaire is related to one of the control or external variable of the study. For control variables, there were age, gender, education level, occupation, payment type, and 3G experience related questions. The value ranges and measurement scales of these variables are given in Table 1. 
Table 1: Value Ranges and Scales of the Control Variables

\begin{tabular}{|l|l|l|}
\hline Variable & Values & Measurement Scale \\
\hline Age & $18-25,26-33,34-41,42+$ & Ordinal \\
\hline Gender & Female, Male & Nominal \\
\hline Education Level & $\begin{array}{l}\text { High school, Bachelors, } \\
\text { Master/PhD }\end{array}$ & Ordinal \\
\hline Occupation & Student, IT, Business, Other & Nominal \\
\hline Payment Type & Prepaid, Postpaid & Nominal \\
\hline Experience & $0,0-1,1-2,2+$ & Ordinal \\
\hline
\end{tabular}

Concerning external variables, perceived usefulness includes four sub questions: perceived ease of use, price, social influence, behavioral intention; while service quality includes three sub questions in the questionnaire. The variable of variety of services includes two sub questions. All questions of external variables are based on 5-point Likert scale.

Among the control variables, age, which is defined as a categorical variable in the questionnaire, is transformed to a ratio scale variable by accepting the mid values of each interval as the estimated age of the respondent. Therefore, age is treated as a continuous variable in the analyses of the study.

Values of the external variables related to perceived usefulness, perceived ease of use, social influence, the variety of service, and the price of $3 \mathrm{G}$ technologies are evaluated in terms of averages. The averages of the sub questions of these factors are calculated and named as AverageofUsefulness, AverageofEase, AverageofInfluence, AverageofVariety, and AverageofPrice respectively. For price variable, the average of the first and third questions is computed since these are questions related to the price of $3 \mathrm{G}$ technology. The second question is evaluated separately and named as Price2, because this question is related to the price of $3 \mathrm{G}$ devices. For service quality variable, all questions are evaluated separately in the dataset (ServiceQuality1, ServiceQuality2, and ServiceQuality3) because each question is related to different aspects of the service quality. ServiceQuality1 is a question about the safety of 3G technology; ServiceQuality2 is about the sensitivity to users' complaints; and ServiceQuality3 is about the speed of this technology. Behavioral intention is the target variable. In order to understand people's behavioral intention about the $3 \mathrm{G}$ usage, opinions about the issues such as quality, supported activities, usefulness of 3G technologies were asked about. The average of these questions are calculated and named as AverageofIntension.

\section{Methodology and Hypotheses}

After data preparation, independent samples t-test, one-way ANOVA and regression analysis were applied to the dataset.

\section{Independent Samples T-test:}

Correlations between the target variable and the other variables were analyzed. In order to analyze the relationships between behavioral intention and the mentioned two control variables: gender and payment type, independent samples t-test were applied. Hypotheses:

$\mathbf{H}_{1}$ : There is a statistically significant difference between consumer's gender and their behavioral intention to use $3 \mathrm{G}$ technology.

$\mathbf{H}_{2}$ : There is a statistically significant difference between consumer's payment type of telecommunication service and their behavioral intention to use $3 \mathrm{G}$ technology.

One-way ANOVA: It was used to analyze the difference between behavioral intention to use 3G technology and the other control variables: education level, experience, and occupation. If significant 
differences were to be found, the Tukey's HSD Post-hoc test was conducted in order to determine which group differs from each other in terms of behavioral intention to use $3 \mathrm{G}$ technology. Hypotheses:

$\mathbf{H}_{3}$ : There is a statistically significant difference between consumers' education level and their behavioral intention to use $3 \mathrm{G}$ technology.

$\mathbf{H}_{4}$ : There is a statistically significant difference between consumers' experience level of 3G technologies and their behavioral intention to use 3G technology.

H$_{5}$ : There is a statistically significant difference between consumers' occupation and their behavioral intention to use $3 \mathrm{G}$ technology.

Correlations: To obtain a measure of the relation between the behavioral intention and each continuous type variable of the study, Pearson Correlation values were analyzed. Thus, for each variable the following hypotheses were tested:

$\mathbf{H}_{6}$ : There is a statistically significant correlation between consumers' age and their behavioral intention to use 3G technology.

$\mathbf{H}_{7}$ : Perceived usefulness has a positive effect on consumers' behavioral intention to use $3 \mathrm{G}$ technology.

$\mathbf{H}_{8}$ : Perceived ease of use has a positive effect on consumers' behavioral intention to use $3 \mathrm{G}$ technology.

H9: Price has a negative effect on consumers' behavioral intention to use $3 \mathrm{G}$ technology.

$\mathbf{H}_{\mathbf{1 0}}$ : The variety of services has a positive effect on consumers' behavioral intention to use $3 \mathrm{G}$ technology.

$\mathbf{H}_{11}$ : Service quality has a positive effect on consumers' behavioral intention to use 3G technology.
$\mathbf{H}_{12}$ : Social influence has an effect on consumers' behavioral intention to use 3G technology.

$\mathbf{H}_{13}$ : Perceived usefulness has an effect on perceived ease of use to use $3 G$ technology.

Multiple Linear Regression: This analysis was undertaken to investigate the significant variables that affect the behavioral intention to use 3G technology. The dependent variable was the average of behavioral intention questions; and the independent variables were all the control and external variables. Dummy variables were created for nominal and ordinal type variables, such as gender, payment type, education level, occupation and experience.

\section{Findings}

The data of the study were entered to SPSS 17.0 for further statistical analysis. In all analyses, a 0.05 significance level was used.

Descriptive Statistics: The sample is formed of $37.3 \%$ female and $62.7 \%$ male over 150 valid responses. Most of the respondents are young people; approximately $82 \%$ of those are between 18 and 33 years old. In terms of education, it is found that $93 \%$ of the respondents have at least a bachelor's degree; therefore it can be claimed that most of the sample are formed of educated people. The highest percentage of the sample belongs to students. Almost half of the sample is constituted from them (48\%). The next highest occupation group is IT sector (24\%). Related to payment type, it is seen that the percentages of prepaid and postpaid respondents are almost equal. Another control variable was experience which is taken into consideration in terms of years of 3G usage. A significant percentage of the respondents (39.3\%) don't use the 3G technology, 29.3\% use 3G technology for less than 1 year, and the remaining use this technology for more than 1 year. According to these results, it may be concluded that the sample is formed with educated, younger, and mostly experienced people in $3 \mathrm{G}$ technologies. 
Descriptive Statistics for external variables are given in Table 2 . The respondents mostly agree with the importance of perceived usefulness, speed of technology, and variety of $3 \mathrm{G}$ services.

Table 2: Descriptive Statistics for External Variables

\begin{tabular}{|l|c|c|c|c|c|}
\hline & $\mathrm{N}$ & Minimum & Maximum & Mean & Std. Deviation \\
\hline Price2 & 150 & 1 & 5 & 3.84 & 1.004 \\
\hline ServiceQuality1 & 150 & 1 & 5 & 3.38 & .880 \\
\hline ServiceQuality2 & 150 & 1 & 5 & 2.99 & .952 \\
\hline ServiceQuality3 & 150 & 1 & 5 & 4.35 & .794 \\
\hline AverageofUsefulness & 150 & 1.00 & 5.00 & 4.0067 & .80003 \\
\hline AverageofEase & 150 & 1.67 & 5.00 & 2.7467 & .50895 \\
\hline AverageofPrice & 150 & 1.00 & 5.00 & 3.5167 & .88881 \\
\hline AverageofVariety & 150 & 1.00 & 5.00 & 3.8933 & .72024 \\
\hline AverageofInfluence & 150 & 1.00 & 5.00 & 3.4400 & .78133 \\
\hline
\end{tabular}

Independent Samples T-Test: According to the results, there is no significant difference between male and female respondents and behavioral intention to use 3G technology $(\mathrm{p}=0.973)$. The similar result is obtained for payment type. There is no significant difference between respondents using different types of payment (prepaid/postpaid) in terms of $3 \mathrm{G}$ technology usage $(\mathrm{p}=0.129)$.

One-Way ANOVA Test: According to the ANOVA results, there are significant differences between education level of people and their intention to use 3G technology $(p=0.001)$. In order to find out the groups which create the difference, Tukey HSD test is applied. The results show that;

- There are significant differences in 3G usage intention of people graduated from high school and those who have bachelor's degree ( $\mathrm{p}=0.005)$.

- There are significant differences in 3G usage intention of people graduated from high school and those who have Master's/PhD degree $(\mathrm{p}=0.002)$.

Similarly, experience is another important factor in behavioral intention of 3G technology. The one-way ANOVA test indicates that there are significant differences between experience in terms of people's 3G usage years and their intention to use $3 \mathrm{G}$ technology $(\mathrm{p}=0.000)$. According to Tukey HSD test results,
- There are significant differences in 3G usage intention of people having no experience and experience for less than 1 year $(p=0.000)$.

- There are significant differences in 3G usage intention of people having no experience and experience between 1 and 2 years $(\mathrm{p}=0.000)$.

- There are significant differences in 3G usage intention of people having no experience and experience for more than 2 years $(p=0.000)$.

Related to occupation, significant differences are valid among people having different occupation types and their behavioral intention to use 3G technology $(p=0.009)$. According to Tukey HSD test results,

- There are significant differences between IT related jobs and other occupations in terms of behavioral intention for $3 \mathrm{G}$ technology $(\mathrm{p}=0.008)$.

Correlations: Pearson correlation test is applied to all external variables including perceived usefulness, perceived ease of use, price, variety of $3 \mathrm{G}$ services, service quality and social influence and age as a control variable to measure their relationship with behavioral intention for 3G technology. According to the results perceived usefulness has a strong effect on adopting 3G technology $(r=0.656 ; \quad p=0.000)$. Perceived ease of use is another factor for 
which the relationship is significant $(\mathrm{r}=0.171 ; \mathrm{p}=0.037)$, but this relationship is not strong like perceived usefulness.

Another important factor is variety of services, since the relationship is significant for $\mathrm{p}=0.000$ value $(\mathrm{r}=0.538)$. It can be concluded that the variety of $3 \mathrm{G}$ services positively affects behavioral intension of $3 G$ usage. The relationships between service quality, in terms of three different questions, and the target variable are analyzed. According to the results, the relationships between speed and 3G usage $(r=0.443 ; p=0.000)$ and safety and 3G usage $(\mathrm{r}=0.486 ; \mathrm{p}=0.000)$ are significant, whereas the relationships between sensitivity to users' complaints and 3G usage $(r=0.128$; $\mathrm{p}=0.120$ ) is not significant. In terms of social influence, there is considerably strong relationship $(\mathrm{r}=0.523 ; \mathrm{p}=0.000)$. Price is another factor which is evaluated as the price of $3 G$ devices and the price of $3 \mathrm{G}$ technology. According to the results, both variables have no effect on $3 G$ usage. Similarly, the relationship between age and the target variable is not found to be significant.

Multiple Regression Analysis: Stepwise method is selected to eliminate the effect of correlation between independent variables (multicollinearity problem) and finds the variables that are directly affecting the dependent variable. According to the results summarized in Table 3 , the F test of the model is found to be significant. The significant variables of the model are Perceived Usefulness, ServiceQuality3 (speed), Social Influence, Variety of Services, Price2 (price of $3 G$ devices), and
Occupation (other sector) entered to the model, respectively. The coefficients of Perceived Usefulness, ServiceQuality3 (speed), Social Influence, and Variety of Services are all positive which indicate that they all have positive effects on the behavioral intention of $3 \mathrm{G}$ usage. Although the coefficient of Price is positive, it negatively affects the behavioral intention, because the related question was about the expensiveness of this technology. In other words, when the people think that $3 \mathrm{G}$ devices are expensive, their willingness to use this technology is negatively affected. Therefore, price of 3G technology devices has a negative effect on behavioral intention. On the other hand, the coefficient of Occupation which refers to other sectors has a negative sign. It can be concluded that people who are working in a sector other than business or IT are less willing to use $3 \mathrm{G}$ technology.

The $R^{2}$ value of the model is 0.627 which indicates considerably strong relationship between the dependent and independent variables of the model. In other words, these variables together can explain the variability of behavioral intension to use $3 \mathrm{G}$ technology at a level of $62.7 \%$ in the population. As a result, behavioral intention to use 3G technology are influenced negatively regarding high prices of $3 \mathrm{G}$ devices, but positively regarding usefulness, service quality, service variety of this technology. Social influence is another important factor that increases the willingness of people on using 3G technologies. Moreover, students or people working in IT/Business sector can adopt this technology easier than others.

Table 3: Regression Analysis Results

\begin{tabular}{|l|c|c|c|c|c|}
\hline Variables & $\mathrm{b}$ & $\mathrm{SEb}$ & Beta $(\beta)$ & $\mathrm{t}$ & Sig. \\
\hline (Constant) & -.976 & .379 & & -2.573 & .011 \\
\hline AverageofUsefulness & .445 & .066 & .411 & 6.782 & .000 \\
\hline ServiceQuality3 & .258 & .061 & .237 & 4.247 & .000 \\
\hline AverageofInfluence & .238 & .066 & .215 & 3.598 & .000 \\
\hline AverageofVariety & .224 & .073 & .186 & 3.080 & .002 \\
\hline Price2 & .103 & .045 & .119 & 2.305 & .023 \\
\hline Dummy-Occupation1 & -.280 & .134 & -.108 & -2.081 & .039 \\
\hline $\mathrm{R}^{2}$ & & & & \\
Adjusted R & .627 & & & & \\
SE Estimate & .611 & & & \\
F & .539 & & & \\
Sig F & 39.981 & & & & \\
\hline
\end{tabular}




\section{Conclusions}

$3 \mathrm{G}$ offers a vertically integrated, top-down, services provider approach to delivering wireless Internet access. This research aims to examine the consumers' attitudes and intentions towards 3G technology. In order to achieve that, the concepts related to the domain of 3G technology were reviewed and a theoretical framework based on TAM and UTAUT was proposed.

According to the results of the study, gender and payment type have no effect on 3G behavioral intention. However, there are significant differences between educational levels. With the increase of education level, people have more tendencies to use this technology, to adopt it and to add it into their daily life. In addition, occupation is another factor which shows a significant difference between groups. Students and people having business/IT related jobs have higher intention to use and adopt 3G technology compared to others. Although occupation and education level are influential factors, age has no impact on technology adoption for $3 \mathrm{G}$ in this study. However, it has always been assumed that young people can adopt technology easier. Since the present sample consists of relatively younger people, no significant differences on $3 \mathrm{G}$ usage have been found among them.

On the other hand, perceived usefulness is a strong determinant of user acceptance, adoption, and usage behavior. In the study, the results show that the respondents strongly heed the usefulness of 3G technology. In addition, there exists a significant relationship between perceived usefulness and perceived ease of use as accepted in UTAUT and TAM models. Another significant result of the study is that variety of services and service quality are influential factors for 3G technology acceptance. Among the service quality properties of 3G technology, most important ones are the speed and safety of this technology. The respondents think that $3 \mathrm{G}$ supported cell phones' price is high and this may affect the intention of $3 \mathrm{G}$ technology negatively. Moreover, social influence is another important factor which positively affects the tendencies of $3 \mathrm{G}$ usage.

For further studies, the questionnaire can be conducted on more people. Moreover, providing variety in participants may enrich the results.

\section{References}

Agarwal, N. K., Wang, Z., Xu, Y. \& Poo, D. C. C. (2007). "Factors Affecting 3G Adoption: An Empirical Study," Proceeding of the 11th Pacific-Asia Conference on Information Systems, 4-6 July, Auckland, New Zealand, 256-270.

Bienstock, C. C., Royne, M. B., Sherell, D. \& Stafford, T. F. (2008). “An Expanded Model of Logistics Service Quality: Incorporating Logistics Information Technology," International Journal of Production Economics, 113, 205-222.

Cheong, J. H. \& Park, M.- C. (2005). "Mobile Internet Acceptance in Korea," Internet Research, 15 (2), 125-140.

Davis, F. D. (1989). "Perceived Usefulness, Perceived Ease of Use, and User Acceptance of Information Technology," MIS Quarterly, 319-340.

Davis, F. D., Bagozzi, R. P. \& Warshaw, P. R. (1989). "User Acceptance of Computer Technology: A comparison of Two Theoretical Models," Management Science, 35 (8), 982-1003.

Fadare, O. G., Babatunde, O. H., Akomolafe, D. T. \& Lawal, O. O. (2011). "Behavioral Intention for Mobile Learning on 3G Mobile Internet Technology in South-West Part of Nigeria," World Journal of Engineering and Pure and Applied Sciences, 1(2), 19-28.

Indrawati, R. M. \& Chew, K.- W. (2010). “A Conceptual Model for Behavioral Intention to Use 3G Mobile Multimedia Services in Indonesia," Proceedings of the International Symposium on Information Technology, Kuala Lumpur.

Karjaluoto, H. (2006). “An Investigation of Third Generation (3G) Mobile Technologies 
and Services," Contemporary Management Research, 2 (2), 91-104.

Kuo, Y.- F. \& Yen, S.- N. (2009). "Towards an Understanding of the Behavioral Intention to Use 3G Mobile Value-Added Services," Computers in Human Behavior, 25, 103-110.

Legris, P., Ingham, J. \& Collerette, P. (2003). "Why Do People Use Information Technology? A Critical Review of the Technology Acceptance Model," Information and Management, 40, 191-204.

Pagani, M. (2004). "Determinants of Adoption of Third Generation Mobile Multimedia Services," Journal of Interactive Marketing, 18 (3) 46-59.

Park, S. Y., Nam, M.- W. \& Cha, S.- B. (2011). 'University Students' Behavioral Intention to Use Mobile Learning: Evaluating the Technology Acceptance Model," British Journal of Educational Technology.

Phuangthong, D. \& Malisawan, S. (2005). “A Study of Behavioral Intention for 3G Mobile Internet Technology: Preliminary Research on Mobile Learning," Proceedings of the Second International Conference on eLearning for Knowledge Based Society, Thailand, 17.1-17.7.

Singh, S., Singh, D. K., Singh, M. K. \& Singh, S. K. (2010). "The Forecasting of 3G Market in India Based on Revised Technology Acceptance Model," International Journal of Next-Generation Networks, 2(2), 61-68.

Suki, N. M. (2011). “Subscribers' Intention Towards Using 3G Mobile Services," Journal of Economics and Behavioral Studies, 2 (2), 67-75.

Suki, N. M. \& Suki, N. M. (2011). "Exploring the Relationship Between Perceived Usefulness, Perceived Ease of Use, Perceived Enjoyment, Attitude and Subscribers' Intention Towards Using 3G Mobile Services," Journal of Information Technology Management, 12(1), 1-7.

Susan, E., Chuleeporn, C. \& Robert, C. (2006). "Investigating Students' Perceptions on Laptop Initiative in Higher
Education: An Extension of the Technology Acceptance Model," Campus-Wide Information Systems, 23 (5), 336 - 349.

Venkatesh, V. (2000). "Determinants of Perceived Ease of Use: Integrating Control, Intrinsic Motivation, and Emotion into the Technology Acceptance Model," Information Systems Research, 11 (4), 342365.

Venkatesh, V. \& Davis, F. D. (2000). “A Theoretical Extension of the Technology Acceptance Model: Four Longitudinal Field Studies," Management Science, 46 (2), 186204.

Venkatesh, V., Morris, M. G., Davis, G. B. \& Davis F. D. (2003). "User Acceptance of Information Technology: Toward A Unified View," MIS Quarterly, 27 (3), 425-478.

Wahid, F. (2007). "Using the Technology Adoption Model to Analyze Internet Adoption and Use Among Men and Women in Indonesia," The Electronic Journal on Information Systems in Developing Countries, 32 (6), 1-8.

Wu, Y.- L., Tao, Y.- H. \& Yang, P.- C. (2008). "The Use of Unified Theory of Acceptance and Use of Technology to Confer the Behavioral Model of 3G Mobile Telecommunication Users," Journal of Statistics \& Management Systems, 11 (5), 919-949. 